\title{
Trace analysis of off-flavor/odor compounds in water using liquid-liquid microextraction coupled with gas chromatography - positive chemical ionization-tandem mass spectrometry
}

\author{
Jian LU ${ }^{1}$, Paul S. WILLS ${ }^{2}$, P. CHRIS WILSON (ه) ${ }^{1}$ \\ 1 Indian River Research and Education Center, University of Florida/IFAS, 2199 South Rock Road, Fort Pierce, FL 34945-3138, USA \\ 2 Harbor Branch Oceanographic Institute at Florida Atlantic University, 5600 U.S. 1 North, Fort Pierce, FL 34946, USA
}

(C) Higher Education Press and Springer-Verlag Berlin Heidelberg 2015

\begin{abstract}
A rapid, inexpensive and laboratory friendly method was developed for analysis of off-flavor/odor compounds in fresh and salt water using gas chromatography with chemical ionization-tandem mass spectrometry. Off-flavor/odor compounds included geosmin, 2methylisoborneol (MIB), 2-isobutyl-3-methyoxypyrazine (IBMP), and 2-isopropyl-3-methoxypyrazine (IPMP). Using this method, a single sample can be extracted within minutes using only $1 \mathrm{~mL}$ of organic solvent. The ion transitions for IPMP, IBMP, MIB, and geosmin were $153>121,167>125,152>95$, and $165>109$, respectively. The linearity of this method for analyzing MIB ranged from 4 to $200 \mathrm{ng} \cdot \mathrm{L}^{-1}$, and from 0.8 to $200 \mathrm{ng} \cdot \mathrm{L}^{-1}$ for the other analytes. Method recoveries ranged from $97 \%$ to $111 \%$ and percent relative standard deviations ranged from $3 \%$ to $9 \%$, indicating that the method is accurate, precise, and reliable.
\end{abstract}

Keywords off-flavor/odor compounds, liquid-liquid microextraction, gas chromatography-tandem mass spectrometry

\section{Introduction}

Taste and odor problems occur in natural and man-made water systems throughout the world. Major contributors to the earthy-musty odors include geosmin, 2-methylisoborneol (MIB), 2-isobutyl-3-methyoxypyrazine (IBMP), and 2-isopropyl-3-methoxypyrazine (IPMP) [1-3]. Odors of these compounds are perceptible at low levels (in the order

Received May 22, 2015; accepted August 25, 2015

E-mail: pcwilson@ufl.edu of $10 \mathrm{ng} \cdot \mathrm{L}^{-1}$ or less) [4,5]. The undesirable effects of these compounds are not restricted to drinking water sources. These chemicals can also cause significant economic losses in the aquaculture industry due to their partitioning into fish flesh. Several studies have documented the transfer of these compounds from water into the marketable flesh of catfish $[3,6,7]$. When released into the culture water within aquaculture facilities, geosmin and MIB are absorbed by lipid-rich fish tissues, which often render the fish unmarketable due to the smell and taste $[8,9]$. For this reason, it is important to have techniques available to enable accurate analysis of these compounds in waters of the aquaculture industry. Likewise, customer dissatisfaction with potable water sources may be reduced if costeffective methods are available for monitoring supplies.

Liquid-liquid extraction (LLE), solid phase extraction (SPE), and solid phase microextraction (SPME) methods have been used for the analysis of off-flavor compounds [10]. Closed loop-stripping analysis (CLSA) has been the most frequently used method for extraction and concentration of taste and odor compounds in water [10-13]. Methods for trace analysis of these chemicals usually require large sample volumes, intensive sample preconcentration procedures, and/or complex equipment [14]. Disadvantages of SPME techniques include expenses related to supplies, conditioning of sorbents can be time consuming, and carry-over effects are common [4,10]. LLE and SPE use large amounts of toxic and expensive organic solvents, are time-consuming and the multiple sample handling steps can result in undesirable crosscontamination [10]. A rapid, cost-effective, selective, laboratory-friendly, and sensitive analytical method for monitoring these compounds is needed.

Many off-flavor/odor compounds, including geosmin 
and MIB, are amenable to gas chromatographic-based analysis methods [11] due to their semi-volatility. Mass spectrometry coupled with gas chromatography (GC-MS) may become a standard analytical method for detection of low concentrations of these compounds [11]. Many of the published GC-MS methods have been run in electron ionization (EI) mode and ion scans were performed in selected ion monitoring (SIM) mode. In addition to EI mode, chemical ionization (CI) is also an ionization technique widely used in mass spectrometry [15]. Chemical ionization imparts less energy into the parent molecule, relative to electron ionization. The lower energy yields less fragmentation, and usually a simpler spectrum, which may increase the peak intensity and enhance analytical sensitivity [15]. This ionization technique is especially useful for compounds that tend to fragment extensively by EI, yielding no fragments sufficient for monitoring and analysis. Tandem mass spectrometry is a technique that involves multiple steps of mass spectrometry selection [15]. Compared with the traditional SIM mode, tandem mass spectrometry (MS/MS) techniques can avoid interferences from many background fragment ions and enhance the sensitivity of the analysis [15]. The goal of this project was to develop and evaluate a rapid, inexpensive and laboratory friendly method for analysis of trace concentrations of off-flavor compounds using GCMS/MS with chemical ionization.

\section{Material and methods}

\subsection{Reagents and materials}

Geosmin (99.9\%), 2-methylisoborneol (MIB) (98.3\%), 2isobutyl-3-methyoxypyrazine (IBMP) (97.5\%), 2-isopropyl-3-methoxypyrazine (IPMP) (99.6\%), and 2,4,6-trichloroanisole (TCA) (99.9\%) were purchased from Supelco (Bellefonte, PA, USA). Standards were individually dissolved in methanol at a concentration of $100 \mu \mathrm{g} \cdot \mathrm{mL}^{-1}$. Hexane was of pesticide grade while methanol was of GC grade (Fisher Scientific, Pittsburgh, PA, USA).

\subsection{Extraction procedure}

The extraction procedure was evaluated by spiking fresh water (from a well on-site at Harbor Branch Oceanographic Institute) and filtered seawater (from the Indian River Lagoon) with the target compounds spiked at a concentration of $10 \mathrm{ng} \cdot \mathrm{L}^{-1}$. No residual concentrations were detected in these water sources prior to spiking. A total of 10 replicates for each water type were evaluated. Water samples were extracted using a micro liquid-liquid extraction technique modified from that of Ma et al. [16]. Water samples $(250 \mathrm{~mL})$ were poured into Teflon separatory funnels. The surrogate, TCA, was spiked at $100 \mathrm{ng} \cdot \mathrm{L}^{-1}$. One $\mathrm{ml}$ of hexane was added. The samples were then extracted by shaking the funnel vigorously by hand for $30 \mathrm{~s}$. The organic layer was then collected using a glass pipette and transferred to a vial for instrument analysis. Collection of the organic layer was facilitated by draining off the aqueous phase leaving the organic layer in the narrow neck of the funnel. Care was taken to not transfer water close to the water-hexane interface. Samples were only extracted once.

\subsection{Instrument analytical method}

The extracts of water samples were analyzed using gas chromatography coupled with tandem mass spectrometry (GC-MS/MS). Analysis was achieved using a Varian 3800 gas chromatograph connected to a Varian 4000 mass spectrometer (Agilent Technologies, Santa Clara, CA, USA). The target compounds were separated using an Rxi$5 \mathrm{MS}(30 \mathrm{~m} \times 0.25 \mathrm{~mm}, 0.25 \mu \mathrm{m}$ film thickness $)$ capillary column (Restek Co., Bellefonte, PA, USA). Helium was used as the carrier gas and was maintained at a constant flow rate of $1 \mathrm{~mL} \cdot \mathrm{min}^{-1}$. The temperatures of the transfer line, trap, and manifold were held at $270^{\circ} \mathrm{C}, 150^{\circ} \mathrm{C}$, and $50^{\circ} \mathrm{C}$, respectively. A sample volume of $1 \mu \mathrm{L}$ was injected in splitless mode. The inlet temperature was held at $280^{\circ} \mathrm{C}$. The oven temperature program was as follows: initial temperature, $60^{\circ} \mathrm{C}$ for $4 \mathrm{~min}$; increased to $200^{\circ} \mathrm{C}$ at $10^{\circ} \mathrm{C} \cdot \mathrm{min}^{-1}$; increased to $280^{\circ} \mathrm{C}$ at $20^{\circ} \mathrm{C} \cdot \mathrm{min}^{-1}$; hold at $280^{\circ} \mathrm{C}$ for $1 \mathrm{~min}$. The solvent delay was set to $5 \mathrm{~min}$. Ionization was performed in positive chemical ionization (CI) mode using methanol as the CI reagent gas. The quantification and confirmation of each analyte was performed by monitoring specific ion transitions for each target compound (Table 1). The excitation voltages for IPMP, IBMP, MIB, geosmin, and TCA were 0.80, 0.62, $0.44,0.53$, and $0.93 \mathrm{~V}$, respectively.

Table 1 Operational parameters for the tandem mass spectrometer scans for off-flavor/odor compounds and the surrogate

\begin{tabular}{|c|c|c|c|c|c|}
\hline compounds & retention time $/ \mathrm{min}$ & precursor ion $/\left(\mathrm{m} \cdot \mathrm{z}^{-1}\right)$ & resonant excitation voltage $/ \mathrm{V}$ & quantitative ions $/\left(\mathrm{m} \cdot \mathrm{z}^{-1}\right)$ & secondary ions $/\left(\mathrm{m} \cdot \mathrm{z}^{-1}\right)$ \\
\hline$\overline{\mathrm{IPMP}}$ & 8.79 & 153 & 0.80 & 121 & 83,138 \\
\hline IBMP & 10.28 & 167 & 0.62 & 125 & 135 \\
\hline MIB & 10.58 & 152 & 0.44 & 95 & 81 \\
\hline TCA (surrogate) & 12.60 & 211 & 0.93 & 196 & 176 \\
\hline Geosmin & 13.86 & 165 & 0.53 & 109 & 95 \\
\hline
\end{tabular}




\subsection{Method calibration and validation}

The analytical method was calibrated with each analyte at 0.8 (except MIB), 4, 10, 20, 40, 100, and $200 \mathrm{ng} \cdot \mathrm{L}^{-1}$. Each analyte was spiked into various blank water samples including fresh water, and sea water to establish a matrix calibration curve. Water samples were extracted, and analyzed following the above-mentioned procedures. Coefficients of determination for calibration curves were required to be at least 0.990 .

To determine the method detection limits (MDL), geosmin $\quad\left(0.8 \mathrm{ng} \cdot \mathrm{L}^{-1}\right), \quad$ IPMP $\quad\left(0.8 \mathrm{ng} \cdot \mathrm{L}^{-1}\right), \quad$ IBMP $\left(0.8 \mathrm{ng} \cdot \mathrm{L}^{-1}\right)$, or MIB $\left(4 \mathrm{ng} \cdot \mathrm{L}^{-1}\right)$ was spiked into blank fresh water and sea water samples. The freshwater also came from the well on-site at Harbor Branch Oceanographic Institute, while the filtered seawater came from the Indian River Lagoon. These concentrations were chosen because they were close to the estimated limit of detection based on a pre-study with spiked water from both sources. Water samples were extracted, and analyzed following the above-mentioned procedures with 7 replicates. The MDLs were calculated as three times the standard deviation of seven replicate runs. The method quantitation limit (MQL) is set at a factor three times the MDL for the target analytes.

\section{Results and discussion}

Typical mass spectra for the four target compounds are shown in Fig. 1. The primary $\mathrm{m} / \mathrm{z}$ ions were $109(100 \%)$ and $95(45 \%)$ for geosmin; $95(100 \%)$ and $81(47 \%)$ for MIB; $125(100 \%)$ and $135(35 \%)$ for IBMP; and 121 (100\%), 83 (70\%), and 138 (33\%) for IPMP. Quantifica- tion of each analyte was performed by monitoring the following ion transitions for each compound: $165>109$ (geosmin), 152>95 (MIB), $167>125$ (IBMP), and $153>121$ (IPMP). A typical chromatogram for a spiked reagent-grade water sample $\left(100 \mathrm{ng} \cdot \mathrm{L}^{-1}\right)$ subject to the liquid-liquid microextraction procedure is shown in Fig. 2. The background was relatively clean under CI mode. IPMP $(8.79 \mathrm{~min})$ was first eluted, followed by IBMP $(10.28 \mathrm{~min})$. The retention times for MIB and geosmin were 10.58 and $13.86 \mathrm{~min}$; while that of TCA (surrogate) was $12.60 \mathrm{~min}$. IPMB, IBMP, and geosmin displayed a relatively high peak intensity; while that of MIB was relatively low.

Integrated peak areas for each compound were $2245 \pm 101$ (IPMP), $4332 \pm 490$ (IBMP), $2787 \pm 410$ (geos$\mathrm{min}$ ), and $519 \pm 66$ (MIB) in fresh water; while peak areas for sea water were $3615 \pm 237$ (IPMP), $7996 \pm 407$ (IBMP), $4697 \pm 145$ (geosmin), and $747 \pm 137$ (MIB) (Fig. 3). The peak areas of all analytes in sea water were significantly higher than those in fresh water, indicating a strong matrix effect on peak intensity. For this reason, matrix-specific calibration curves were subsequently constructed and used to minimize the influence of matrix effects on the analysis. The linearity of this method for analyzing MIB was investigated over the range of 4-200 $\mathrm{ng} \cdot \mathrm{L}^{-1}$, while that for analyzing the other analytes was $0.8-200 \mathrm{ng} \cdot \mathrm{L}^{-1}$ (Table 2 ). Correlation coefficients were all greater than 0.990 . The MDLs/MQLs were $0.2 / 0.6 \mathrm{ng} \cdot \mathrm{L}^{-1} \quad$ (geosmin), $1.2 / 3.6 \mathrm{ng} \cdot \mathrm{L}^{-1}$ (MIB), $0.1 / 0.3 \mathrm{ng} \cdot \mathrm{L}^{-1}$ (IBMP), and $0.2 / 0.6 \mathrm{ng} \cdot \mathrm{L}^{-1}$ (IPMP). Analyte recoveries ranged from $102 \%$ to $109 \%$ in fresh water while those in sea water ranged from $97 \%$ to $111 \%$ (Table 3 ). The high recoveries indicate that this method can reliably detect and accurately
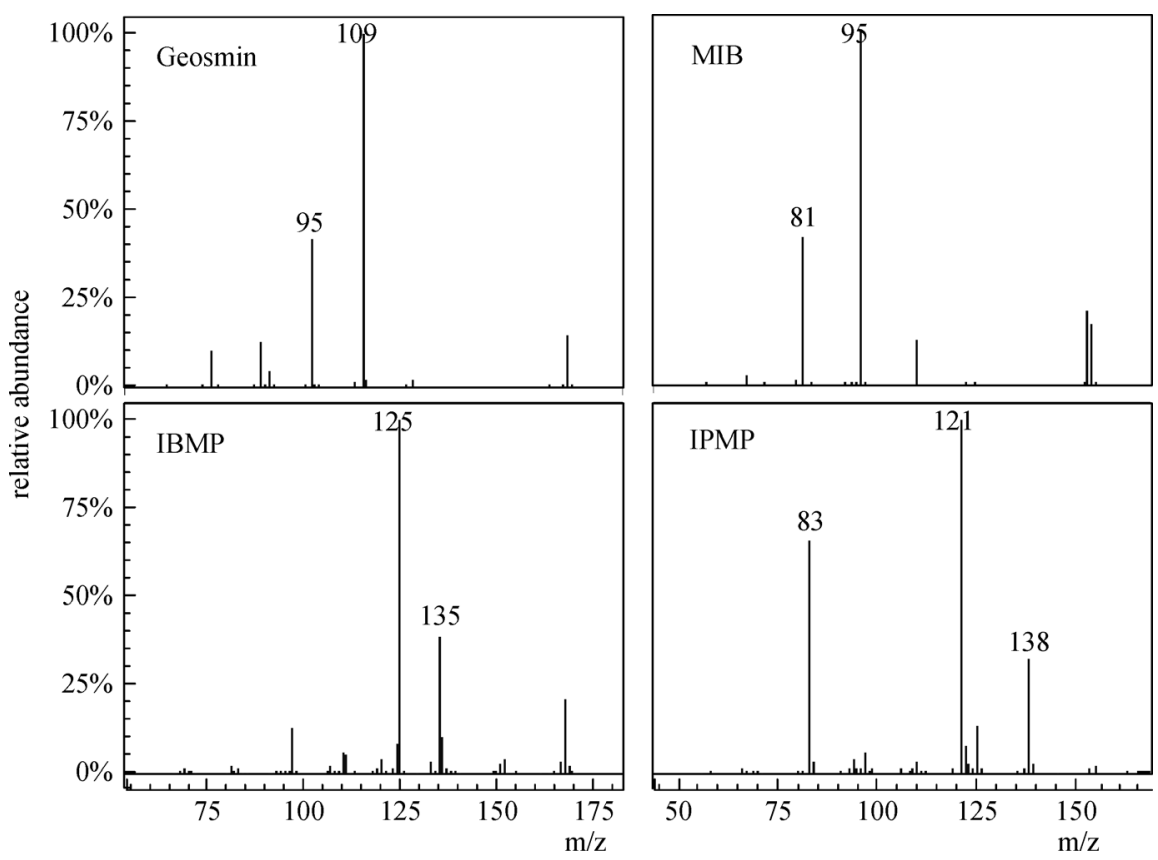

Fig. 1 Typical mass spectra for geosmin, MIB, IBMP, and IPMP 


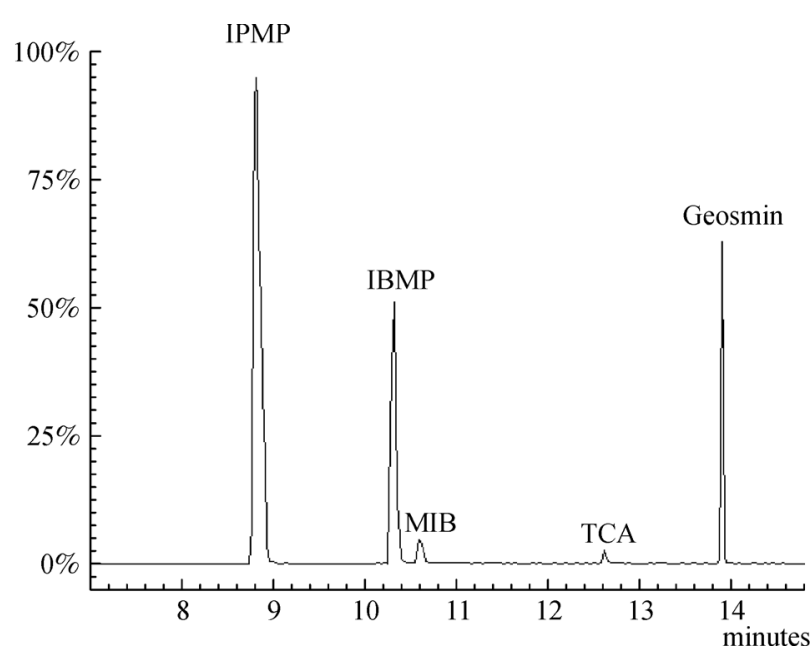

Fig. 2 Typical chromatogram from a spiked nano-pure water sample $\left(100 \mathrm{ng} \cdot \mathrm{L}^{-1}\right)$ extracted using the liquid-liquid microextraction method coupled with gas chromatography-positive chemical ionization tandem mass spectrometry analysis

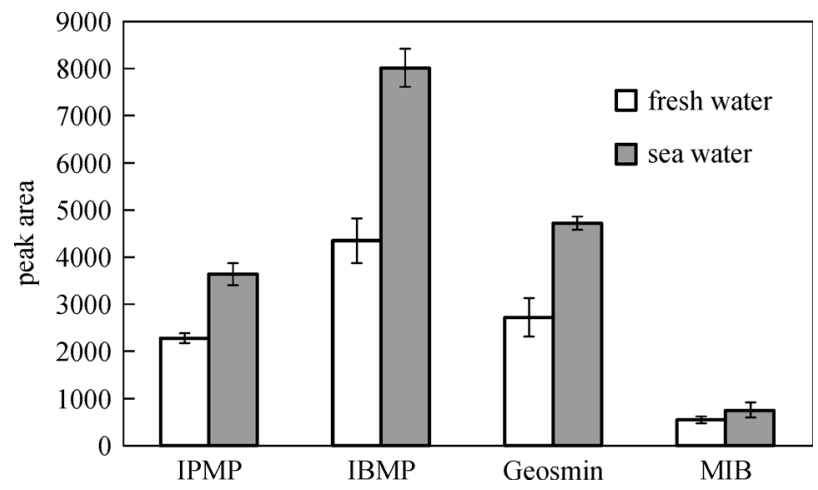

Fig. 3 Effect of water types (fresh vs. salt) on peak intensity of target off-flavor/odor compounds. Each analyte was spiked at the concentration of $100 \mathrm{ng} \cdot \mathrm{L}^{-1}$

quantitate the compounds. The RSD ranged from 3\% to $9 \%$, suggesting that the method is also precise.
The extraction method developed is simple, rapid, and laboratory friendly. Extraction of a single sample was completed within five minutes; as opposed to requiring more than 20 min for SPME procedures [17,18]. Furthermore, sample throughput using SPME methods is limited by the number of SPME devices available. In comparison, up to 12 samples may be extracted within $1 \mathrm{~h}$ using the current method. Consumption of organic solvents is lower compared to other methods. Only $1 \mathrm{ml}$ of organic solvent is needed to extract one water sample, which is much lower than the volume required for traditional liquid-liquid extraction $(5 \mathrm{ml})$ [18] and SPE extraction methods $(>10 \mathrm{~mL})[16]$.

Recoveries of MIB and geosmin in the present study were higher than reported by Ma et al. [16], even though both extracted using $1 \mathrm{~mL}$ of hexane. In their study, recoveries ranged from 49 to $63 \%$ (MIB) and 80-85\% (geosmin); compared to recoveries of $97 \%-106 \%$ in the current study. These differences are likely due to several factors. One significant difference between the two methods is that Ma et al. [16] used a stirring device to distribute the hexane throughout the sample, while we vigorously shook the samples for $3 \mathrm{~min}$. It is likely that the vigorous shaking may have distributed the hexane more uniformly throughout the samples, allowing for more efficient partitioning from the water to the hexane. The type of matrix also differs between the two studies. Ma et al. developed their method for use with drinking water, which is relatively clean. In contrast, the present study used well water and filtered salt water from the Indian River Lagoon estuary. Strong matrix effects on the peak intensity of the compounds were observed, requiring use of matrixmatched standards. Due to the use of matrix calibration techniques, recoveries were much higher than those reported in many studies $[3,16,18,19]$. Relative standard deviations $(\%)$ were similar $(<10 \%)$ between both studies [16]. Since various sources of water can be used for potable water supplies and in aquaculture systems, the use of matrix-matched calibration curves is recommended for accurate quantification. MDLs for this CI-MS/MS method were also lower for these off-flavor compounds than those

Table 2 Linear range and method detection limits for off-flavor/odor compounds

\begin{tabular}{|c|c|c|c|c|c|}
\hline compound & matrix & range/(ng $\left.\cdot \mathrm{L}^{-1}\right)$ & $R^{2}$ & $\mathrm{MDL} /\left(\mathrm{ng} \cdot \mathrm{L}^{-1}\right)$ & $\mathrm{MQL} /\left(\mathrm{ng} \cdot \mathrm{L}^{-1}\right)$ \\
\hline \multirow[t]{2}{*}{ Geosmin } & fresh water & $0.8-200$ & 0.999 & 0.2 & 0.6 \\
\hline & sea water & $0.8-200$ & 0.993 & 0.2 & 0.6 \\
\hline \multirow[t]{2}{*}{ MIB } & fresh water & $4-200$ & 0.999 & 1.2 & 3.6 \\
\hline & sea water & $4-200$ & 0.998 & 1.2 & 3.6 \\
\hline \multirow[t]{2}{*}{ IBMP } & fresh water & $0.8-200$ & 0.992 & 0.1 & 0.3 \\
\hline & sea water & $0.8-200$ & 0.993 & 0.1 & 0.3 \\
\hline \multirow[t]{2}{*}{ IPMP } & fresh water & $0.8-200$ & 0.997 & 0.2 & 0.6 \\
\hline & sea water & $0.8-200$ & 0.994 & 0.2 & 0.6 \\
\hline
\end{tabular}


Table 3 Recovery of off-flavor/odor compounds from fresh water and sea water

\begin{tabular}{lcc}
\hline \multirow{2}{*}{ compounds } & \multicolumn{2}{c}{$\%$ recovery (\% RSD) } \\
\cline { 2 - 3 } & fresh water & sea water \\
\hline IPMP & $109(5)$ & $111(5)$ \\
IBMP & $109(3)$ & $107(3)$ \\
MIB & $106(9)$ & $97(9)$ \\
Geosmin & $102(4)$ & $104(9)$ \\
\hline
\end{tabular}

reported for a SPME-EI-MS/MS method [4], indicating a potential advantage for analysis of off-flavor compounds.

\section{Conclusions}

A simple, rapid, and efficient extraction and analysis method for trace concentrations of off-flavor/odor compounds in water was developed and evaluated. The method is useful (without dilution) for concentrations ranging from 0.8 to $200 \mathrm{ng} \cdot \mathrm{L}^{-1}$ for geosmin, IPMP, and IBMP; and 4-200 $\mathrm{ng} \cdot \mathrm{L}^{-1}$ for MIB. Good precision $(\% \mathrm{RSD}<10 \%)$ and high recoveries $(97 \%-111 \%)$ were also observed. The current method also identified new transitions for all target analytes for use with CI mode as compared to EI mode, demonstrating an alternative tandem mass spectrometry method for the analysis of off-flavor compounds.

Acknowledgements We thank the Florida Department of Agriculture and Consumer Services, Aquaculture Review Council for funding this work (FDACS Contract No. 18491). We thank Mr. Christopher Robinson for technical assistance and matrix sample collection. We also thank the reviewers for their suggestions and critical comments, which greatly improved this manuscript.

\section{References}

1. Taylor W D, Losee R F, Torobin M, Izaguirre G, Sass D, Khiari D, Atasi K. Early warning and management of surface water taste-andodor events. American Water Works Association (AWWA), Denver, CO, USA, 2006

2. Izaguirre G, Taylor W D. A guide to geosmin- and MIB-producing cyanobacteria in the United States. Water Science and Technology, 2004, 49(9): 19-24

3. Ma K, Zhang J N, Zhao M, He Y J. Accurate analysis of trace earthy-musty odorants in water by headspace solid phase microextraction gas chromatography-mass spectrometry. Journal of Separation Science, 2012, 35(12): 1494-1501

4. Parinet J, Rodriguez M J, Serodes J, Proulx F. Automated analysis of geosmin, 2-methyl-isoborneol, 2-isopropyl-3-methoxypyrazine, 2-isobutyl-3-methoxypyrazine and 2,4,6-trichloroanisole in water by SPME-GC-ITDMS/MS. International Journal of Environmental Analytical Chemistry, 2011, 91(6): 505-515
5. Salemi A, Lacorte S, Bagheri H, Barceló D. Automated trace determination of earthy-musty odorous compounds in water samples by on-line purge-and-trap-gas chromatography-mass spectrometry. Journal of Chromatography. A, 2006, 1136(2): 170-175

6. Grimm C C, Lloyd S W, Batista R, Zimba P V. Using microwave distillation-solid-phase microextraction-gas chromatography-mass spectrometry for analyzing fish tissue. Journal of Chromatographic Science, 2000, 38(7): 289-296

7. Grimm C C, Lloyd S W, Zimba P V. Instrumental versus sensory detection of off-flavors in farm-raised channel catfish. Aquaculture (Amsterdam, Netherlands), 2004, 236(1-4): 309-319

8. Guttman L, van Rijn J. Isolation of bacteria capable of growth with 2-methylisoborneol and geosmin as the sole carbon and energy sources. Applied and Environmental Microbiology, 2012, 78(2): 363-370

9. Howgate P. Tainting of farmed fish by geosmin and 2-methyl-isoborneeol: a review of sensory aspects and uptake/depuration. Aquaculture (Amsterdam, Netherlands), 2004, 234(1-4): 155-181

10. Cortada C, Vidal L, Canals A. Determination of geosmin and 2methylisoborneol in water and wine samples by ultrasound-assisted dispersive liquid-liquid microextraction coupled to gas chromatography-mass spectrometry. Journal of Chromatography. A, 2011, 1218(1): 17-22

11. Shin H, Ahn H. Simple, rapid, and sensitive determination of odorous compounds in water by GC-MS. Chromatographia, 2004, 59: $107-113$

12. Hassett A J, Rohwer E R. Analysis of odorous compounds in water by isolation by closed-loop stripping with a multichannel silicone rubber trap followed by gas chromatography-mass spectrometry. Journal of Chromatography. A, 1999, 849(2): 521-528

13. Zander A K, Pingert P. Membrane-based extraction for detection of tastes and odors in water. Water Research, 1997, 31(2): 301-309

14. Sung Y H, Li T Y, Huang S D. Analysis of earthy and musty odors in water samples by solid-phase microextraction coupled with gas chromatography/ion trap mass spectrometry. Talanta, 2005, 65(2): 518-524

15. Van Bramer S E. Introduction to Mass Spectrometry. Widener University, Department of Chemistry, September 2, 1998. Available online http://www.science.widener.edu/svb/massspec/massspec.pdf

16. Ma X, Gao N, Chen B, Li Q, Zhang Q, Gu G. Detection of geosmin and 2-methylisoborneol by liquid-liquid extraction-gas chromatograph mass spectrum (LLE-GCMS) and solid phase extraction-gas chromatograph mass spectrum (SPE-GCMS). Frontiers of Environmental Science \& Engineering in China, 2007, 1(3): 286-291

17. Parinet J, Rodriguez M J, Sérodes J B. Modelling geosmin concentrations in three sources of raw water in Quebec, Canada. Environmental Monitoring and Assessment, 2013, 185(1): 95-111

18. Hsieh W, Hung W, Wang G, Hsieh S, Lin T. Effect of $\mathrm{pH}$ on the analysis of 2-MIB and geosmin in Water. Water, Air, and Soil Pollution, 2012, 223(2): 715-721

19. Zhang L, Hu R, Yang Z. Routine analysis of off-flavor compounds in water at sub-part-per-trillion level by large-volume injection $\mathrm{GC} /$ MS with programmable temperature vaporizing inlet. Water Research, 2006, 40(4): 699-709 